Research Paper

\title{
Tumor-targeting Salmonella typhimurium A1-R regresses an osteosarcoma in a patient-derived xenograft model resistant to a molecular-targeting drug
}

\author{
Takashi Murakami ${ }^{1,2,3}$, Kentaro Igarashi ${ }^{1}$, Kei Kawaguchi ${ }^{1}$, Tasuku Kiyuna ${ }^{1}$, Yong \\ Zhang $^{1}$, Ming Zhao ${ }^{1}$, Yukihiko Hiroshima ${ }^{3}$, Scott D. Nelson ${ }^{5}$, Sarah M. Dry ${ }^{5}$, Yunfeng \\ $\mathbf{L i}^{5}$, Jane Yanagawa ${ }^{6}$, Tara Russell ${ }^{6}$, Noah Federman', Arun Singh ${ }^{4}$, Irmina Elliott ${ }^{6}$, \\ Ryusei Matsuyama ${ }^{3}$, Takashi Chishima ${ }^{3}, K^{\prime}$ uniya Tanaka ${ }^{3}$, Itaru Endo, Fritz C. \\ Eilber $^{6}$, Robert M. Hoffman ${ }^{1,2}$ \\ ${ }^{1}$ AntiCancer, Inc., San Diego, California, USA \\ ${ }^{2}$ Department of Surgery, University of California, San Diego, California, USA \\ ${ }^{3}$ Department of Gastroenterological Surgery, Graduate School of Medicine, Yokohama City University, Yokohama, Japan \\ ${ }^{4}$ Division of Hematology-Oncology, University of California, Los Angeles, California, USA \\ ${ }^{5}$ Department of Pathology, University of California Los Angeles, California, USA \\ ${ }^{6}$ Division of Surgical Oncology, University of California, Los Angeles, California, USA \\ ${ }^{7}$ Department of Pediatrics and Department of Orthopaedics, David Geffen School of Medicine, Mattel Children's Hospital, \\ UCLA's Jonsson Comprehensive Cancer Center, University of California, Los Angeles, California, USA \\ Correspondence to: Robert M. Hoffman, email: all@anticancer.com \\ Fritz C. Eilber, email: fceilber@mednet.ucla.edu \\ Keywords: osteosarcoma, nude mouse, patient-derived xenograft, Salmonella typhimurium A 1-R, tumor-targeting \\ Received: October 20, 2016 Accepted: November 16, 2016 Published: December 20, 2016
}

\section{ABSTRACT}

Osteosarcoma occurs mostly in children and young adults, who are treated with multiple agents in combination with limb-salvage surgery. However, the overall 5-year survival rate for patients with recurrent or metastatic osteosarcoma is 20$\mathbf{3 0} \%$ which has not improved significantly over $\mathbf{3 0}$ years. Refractory patients would benefit from precise individualized therapy. We report here that a patient-derived osteosarcoma growing in a subcutaneous nude-mouse model was regressed by tumortargeting Salmonella typhimurium A1-R (S. typhimurium A1-R, $\mathrm{p}<0.001$ compared to untreated control). The osteosarcoma was only partially sensitive to the moleculartargeting drug sorafenib, which did not arrest its growth. S. typhimurium A1-R was significantly more effective than sorafenib $(P<0.001)$. S. typhimurium grew in the treated tumors and caused extensive necrosis of the tumor tissue. These data show that S. typhimurium A1-R is powerful therapy for an osteosarcoma patient-derived xenograft model.

\section{INTRODUCTION}

The tumor-targeting amino-acid-auxotrophic strain Salmonella typhimurium (S. typhimurium) A1-R is attenuated by auxotrophic mutations for Arg and Leu [1]. S. typhimurium A1-R has also been selected for high tumor virulence in vivo. S. typhimurium A1-R has been shown to be effective against all major types of human cancer in nude mouse models including: cancers of the prostate [1-3], breast [4-6], pancreas [7-11], and ovary [12, 13], as well as soft tissue sarcoma [14, 15] and glioma [16, 17]. S. typhimurium A1-R was also effective against high-grade osteosarcoma, including lung metastasis [18], breast-cancer brain metastasis [19], and experimental breast-cancer bone metastasis [20] in orthotopic mouse models of human cancer cell lines. S. typhimurium A1-R was also shown to be effective on pancreatic cancer stem cells [9], and in combination with anti-angiogenic agents [11]. S. typhimurium A1-R was also effective against cervical cancer [21], melanoma [22], soft-tissue sarcoma [14], 
and pancreatic cancer $[10,11]$ patient-derived orthotopic xenograft (PDOX) mouse models.

In recent studies, $S$. typhimurium A1-R was shown to be effective in a patient-derived orthotopic xenograft (PDOX) model of high-grade undifferentiated pleomorphic soft-tissue sarcoma (UP-STS) grown orthotopically in the right biceps femoris muscle of nude mice. Histological examination demonstrated eradication of the tumor treated with S. typhimurium A1-R followed by doxorubicin (DOX) [15].

S. typhimurium A1-R was also shown recently to be effective against a PDOX mouse model of follicular dendritic-cell sarcoma (FDCS) that was established in the biceps muscle of nude mice. The FDCS PDOX was resistant to both DOX and NVP-BEZ235 dactolisib (BEZ), but was sensitive to S. typhimurium A1-R [23].

Osteosarcoma occurs mostly in children and young adults $[23,24]$, who are treated with multiple agents in combination with limb-salvage surgery. However, the overall 5-year survival rate for patients with recurrent or metastatic osteosarcoma is $20-30 \%$, which has not improved significantly over 30 years [25]. Refractory patients would benefit from precise individualized therapy.

In the present study, we used a patient-derived mouse xenograft model of osteosarcoma to demonstrate much higher efficacy of S. typhimurium A1-R administered by intratumor (i.t.) injection than the molecular-targeting drug, sorafenib.

\section{RESULTS AND DISCUSSION}

\section{Comparison of the histology of the original patient tumor and mouse-grown patient tumor}

Both the original patient tumor (Figure 1A) and the mouse-grown patient tumor (Figure 1B) contained

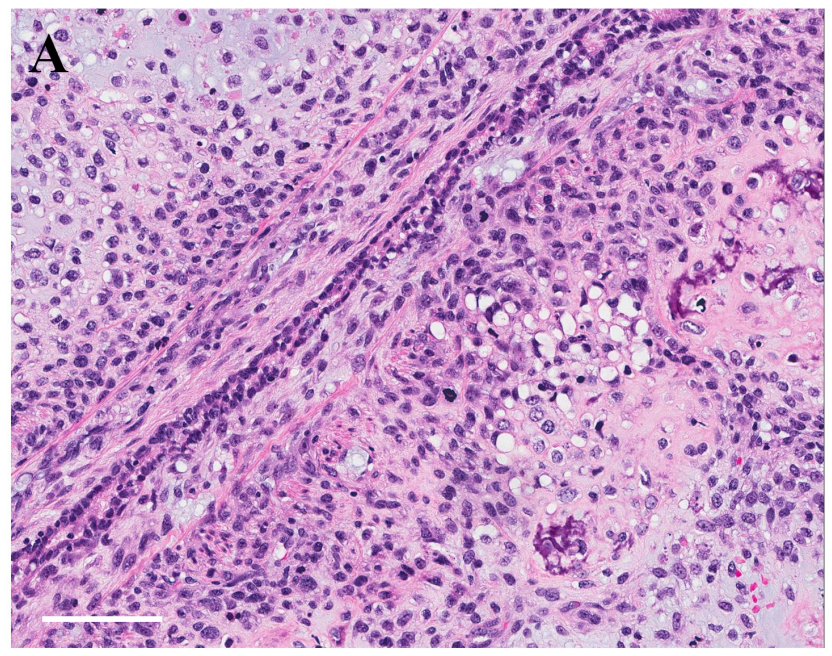

neoplastic chondroid matrix occupied by anaplastic cells. Both the original patient tumor and the mousegrown patient tumor had hypercellular areas populated by anaplastic cancer cells displaying nuclear pleomorphism, coarse and hyperchromatic chromatin and abundant mitotic figures.

\section{Intra-tumor administration of $S$. typhimurium A1-R was highly-effective, in contrast to sorafenib, in a patient-derived osteosarcoma xenograft model}

Nude mice were randomized into 3 groups: untreated control; treated group with sorafenib $(10 \mathrm{mg} /$ kg, p.o., 5 days a week, for 3 weeks); and treated with $S$. typhimurium A1-R $\left(2.5 \times 10^{7}\right.$ colony forming units [CFU], by intra-tumor [i.t.] injection, weekly, for 3 weeks). All tumors were measured twice a week.

Sorafenib significantly reduced tumor growth $(P<0.001)$, but the tumors continued to grow (Figure 2$)$. In contrast, tumors treated with $S$. typhimurium A1-R regressed and were significantly smaller than sorafenibtreated tumors at the end of the study $(P<0.001)$. Body weight range in all mice was from 26.6 to $31.1 \mathrm{~g}$ on day 1. There was no significant difference in body weight between the control group and treated groups at any time points.

\section{S. typhimurium A1-R growth in the treated tumors}

S. typhimurium, expressing green fluorescent protein (GFP), was cultured in serial dilution from supernatants of tumor homogenates. Fluorescent bacteria were detected at all dilutions, indicating they were growing in the treated tumors (Figure 3).

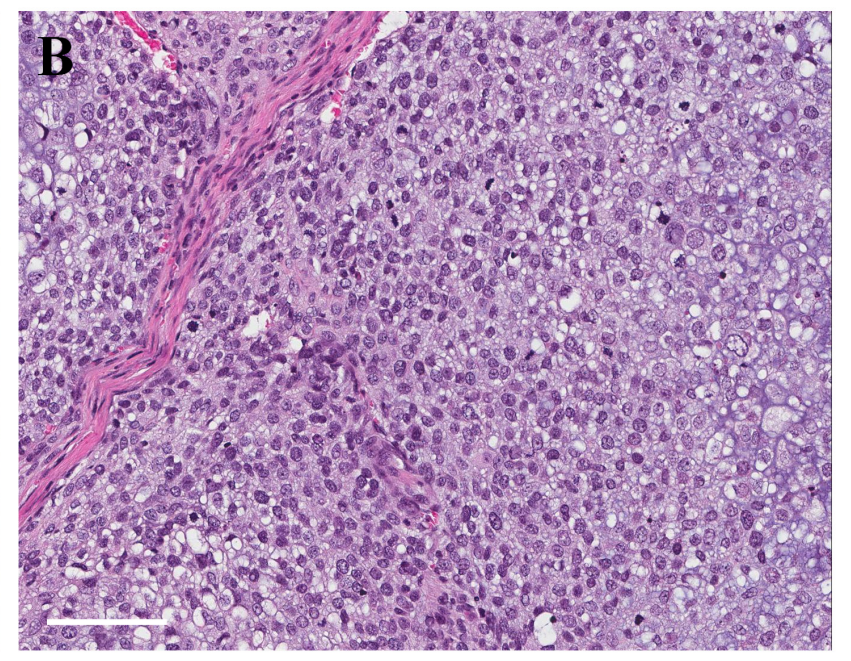

Figure 1: Hematoxylin and eosin (H\&E) staining of original patient tumor and mouse grown tumor. A. Original patient tumor (lung metastasis); B. Untreated patient tumor grown in nude mouse. Scale bars: $100 \mu \mathrm{m}$. 


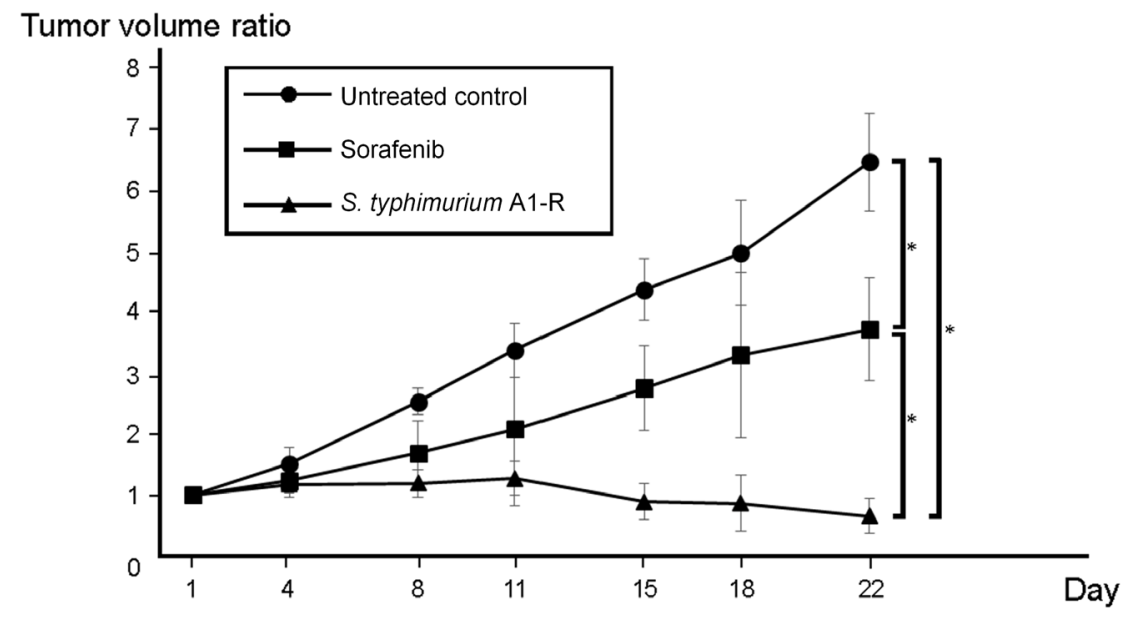

Figure 2: Intratumor (i.t.) administration of Salmonella typhimurium (S. typhimurium) A1-R regresses a patient-derived osteosarcoma xenograft model. Eighteen subcutaneous tumors in nude mice were randomized into 3 groups: untreated control ( $\mathrm{n}=6$ ), treated group with sorafenib $\left(\mathrm{n}=6 ; 10 \mathrm{mg} / \mathrm{kg}\right.$, p.o., 5 days a week, for 3 weeks), and treated with $S$. typhimurium $\mathrm{A} 1-\mathrm{R}\left(\mathrm{n}=6 ; 2.5 \times 10^{7}\right.$ colony forming units [CFU], intratumoral injection, weekly, 3 weeks). All tumors were measured twice a week and tumor volume was calculated using the following equation: Tumor volume $\left(\mathrm{mm}^{3}\right)=$ tumor length $(\mathrm{mm}) \times$ tumor width $(\mathrm{mm}) \times$ tumor width $(\mathrm{mm}) \times 1 / 2$. Both sorafenib and S. typhimurium A1-R effectively reduced tumor growth. In addition, tumors treated with S. typhimurium A1-R achieved regression and were significantly smaller than sorafenib-treated tumors. Body weight was not lost in any mice. ${ }^{*} \mathrm{P}<0.001$. Error bars: $\pm 1 \mathrm{SD}$.

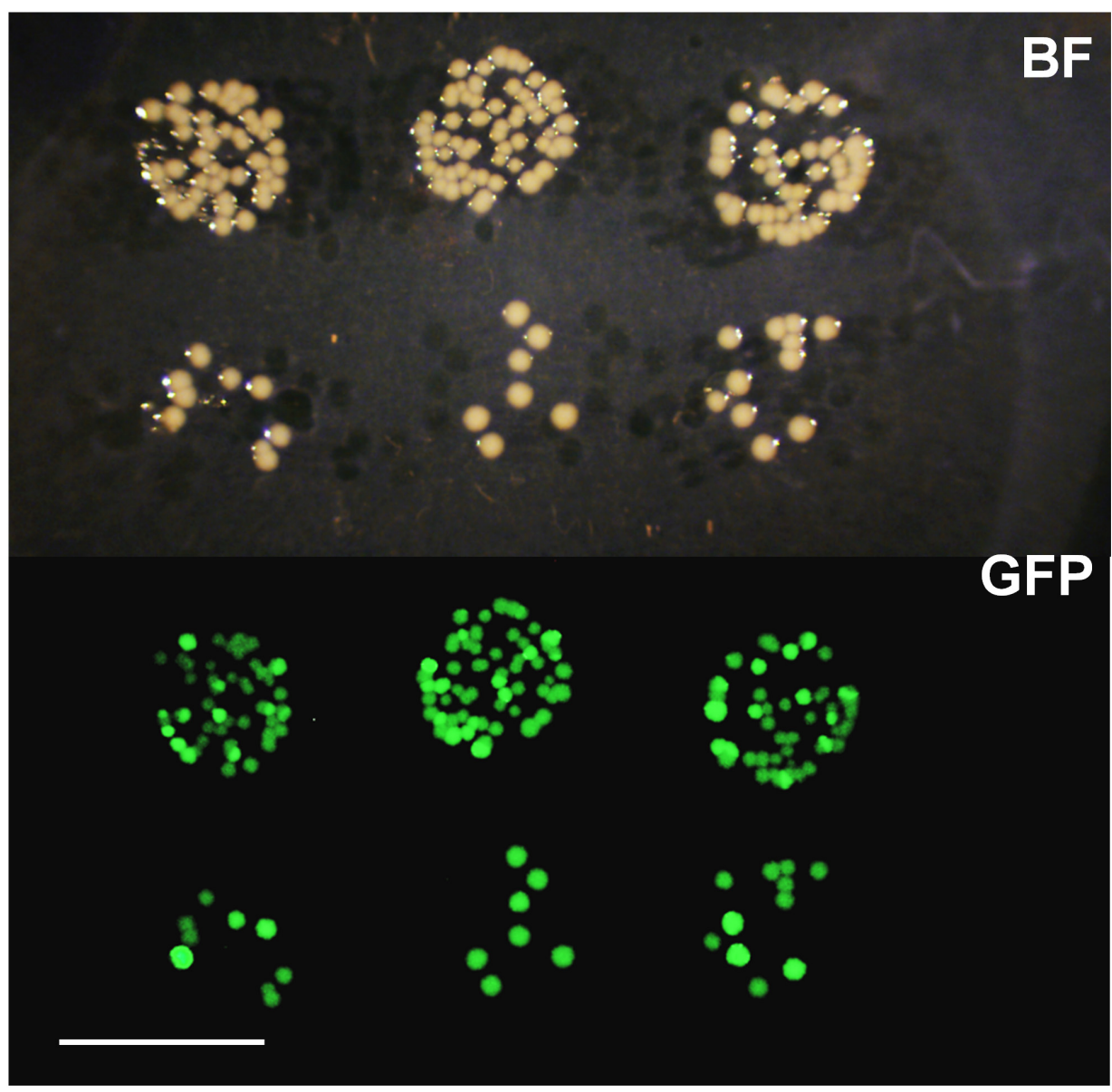

Figure 3: Culture of S. typhimurium from treated tumors. Tumors were homogenized 48 hours after intra-tumor (i.t.) administration of S. typhimurium expressing GFP. Supernatants of the tumor homogenates were serially diluted and grown on agar medium for 12 hours and imaged with the OV100. Please see Materials and Methods. BF; bright field, GFP; green fluorescent protein. Scale bar: 10 mm. 


\section{Effect of S. typhimurium on tumor histology}

S. typhimurium caused extensive necrosis in the treated tumors as visualized in hematoxylin and eosin (H\&E)-stained tumors (Figure 4).

Sorafenib, a multi-kinase inhibitor that blocks VEGFR, PDGFR, MAPK, and KIT, was previously shown to have efficacy against recurrent or un-resectable osteosarcoma as well as metastatic or recurrent angiosarcoma in Phase II clinical studies [26, 27].

$S$. typhimurium A1-R, in addition to being effective against the major types of human cancer in orthotopic nude mouse models [1-17, 21, 22], has been shown to be effective in patient-derived models of pancreatic cancer $[10,11]$, soft-tissue sarcoma [14, $15,23]$ and melanoma [22]. In the present study, we now show that $S$. typhimurium A1-R could regress an osteosarcoma in a patient-derived model in contrast to sorafenib which could not.

Future experiments will examine efficacy of $S$. typhimurium A1-R against PDOX models of osteosarcoma and then in patients. Recently, the tumor- targeting obligate anaerobe Clostridium novyi NT has shown efficacy in leiomyosarcoma patients treated i.t. [28]. Bacterial therapy of cancer, after 80 years, has returned to the clinic [29].

Our group has developed many mouse models and treatment strategies for osteosarcoma [18, 30-38]. Bacterial therapy maybe the most efficacious.

Bacteria have important advantages for the treatment of cancer. Many bacteria naturally target tumors and they can be genetically-manipulated to improve selective tumor targeting and to reduce infection of normal tissue. Bacteria can directly kill infected cancer cells and possibly enhance immune effects against the tumor, even when tumors are drug resistant. Bacteria can grow in, and are not readily cleared from, infected tumors. In addition, bacterial targeting may not be limited by poor tumor vasculature [29].

Previously-developed concepts and strategies of highly-selective tumor targeting can take advantage of molecular targeting of tumors, including tissue-selective therapy which focuses on unique differences between normal and tumor tissues [39-44].

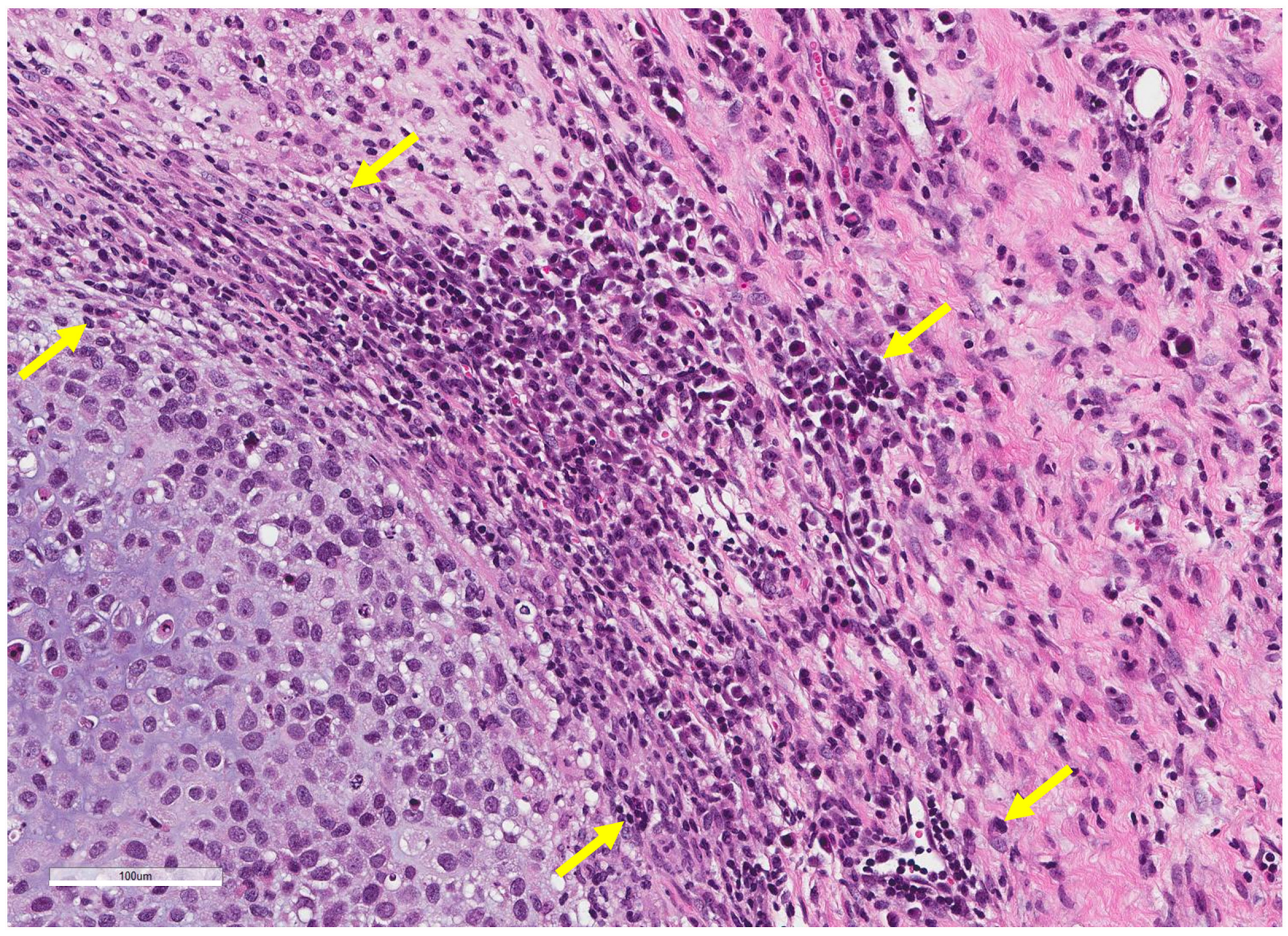

Figure 4: Effect of $\boldsymbol{S}$. typhimurium on tumor histology. Tumors were resected from nude mice at autospy, fixed in formalin, embedded in paraffin, sectioned and stained with hematoxylin and eosin (H\&E) by standard methods. The figure shows the histology of an osteosarcoma treated with S. typhimurium A1-R. Necrotic areas are indicated by yellow arrows. Scale bar: $100 \mu \mathrm{m}$. 


\section{MATERIALS AND METHODS}

Mice

Athymic $n u / n u$ male nude mice (AntiCancer Inc., San Diego, CA), 4-6 weeks old, were used in this study. All animal studies were conducted with an AntiCancer Institutional Animal Care and Use Committee (IACUC)protocol specifically approved for this study, which described the duration of the experiment, the frequency of animal monitoring, the survival aspects of the study, and any anticipated maximum tumor volume or weight loss thresholds at which animals would be euthanized, and in accordance with the principals and procedures outlined in the Guide for the Care and Use of Laboratory Animals, $8^{\text {th }}$ edition, under PHS Assurance Number A3873-1. Animals were anesthetized by subcutaneous injection of a $0.02 \mathrm{ml}$ solution of $80-100 \mathrm{mg} / \mathrm{kg}$ ketamine, $10 \mathrm{mg} / \mathrm{kg}$ xylazine, and $3 \mathrm{mg} / \mathrm{kg}$ acepromazine maleate. Ibuprofen $(7.5 \mathrm{mg} /$ $\mathrm{kg}$ orally in drinking water every 24 hours for 7 days post-surgery) was used in order to provide analgesia postoperatively in the surgically-treated animals.

\section{Patient-derived tumor}

The study was reviewed and approved by the UCLA Institutional Review Board (IRB \#10-001857) before the study began. Written informed consent was obtained from the patient as part of the above-mentioned UCLA Institutional Review Board-approved protocol. A 16-year old patient with localized left distal femoral high-grade osteosarcoma underwent limb salvage distal femoral replacement. One year later, three bilateral metachronous pulmonary metastases appeared. The patient was treated with curative surgery at the Division of Surgical Oncology, University of California, Los Angeles (UCLA). The patient received chemotherapy using methotrexate, cisplatinum and doxorubicin (MAP) peri-operatively.

\section{Establishment of a mouse model of osteosarcoma by subcutaneous transplantation}

A fresh sample of the osteosarcoma metastasized to the lung was obtained and transported immediately to the laboratory at AntiCancer, Inc., on wet ice. The sample was cut into $5 \mathrm{~mm}$ fragments and implanted subcutaneously in nude mice [15]. Implanted tumors were established in 4 weeks. The established tumor was cut into $5 \mathrm{~mm}$ fragments, then these fragments were implanted subcutaneously to the flank in nude mice for the treatment study.

\section{Preparation and administration of S. typhimurium A1-R}

GFP-expressing $S$. typhimurium A1-R bacteria (AntiCancer, Inc., San Diego, CA, USA) were grown overnight on LB medium and then diluted 1:10 in LB medium. Bacteria were harvested at late-log phase, washed with PBS, and then diluted in PBS $[1,3,4]$.

\section{Bacterial culture}

To demonstrate bacterial viability in the treated tumor, a subcutaneous xenograft mouse model was used. Forty-eight hours after S. typhimurium A1-R i.t. injection $\left(2.5 \times 10^{7} \mathrm{CFU}\right.$ in $\left.50 \mu \mathrm{l} \mathrm{PBS}\right)$, the treated tumor was homogenized, then suspended in PBS (phosphate-buffered saline, Corning, New York, NY). The suspension was serially diluted, then cultured in LB agar for 12 hours. GFP-expressing colonies of $S$. typhimurium A1-R were detected by the OV100 Small Animal Imaging System (Olympus, Tokyo, Japan) [45].

\section{Treatment protocol}

Ten days after implantation, tumors reached 9 $\mathrm{mm}$ in diameter. Tumor-bearing mice were randomized into the following 3 groups of 6 mice each: G1, control without treatment ( $\mathrm{n}=6) ; \mathrm{G} 2$, treated with $S$. typhimurium $\mathrm{A} 1-\mathrm{R}\left(2.5 \times 10^{7} \mathrm{CFU}\right.$ in $50 \mu \mathrm{l} \mathrm{PBS}$, i.t. injection), once a week, for 3 weeks $(n=6)$; G3, treated with sorafenib (Selleckchem, Houston, TX, S7397), $10 \mathrm{mg} / \mathrm{kg}$, p.o., 5 days a week, for 3 weeks $(n=6)$. Tumor length, width and mouse body weight were measured twice in a week. Tumor volume was calculated with the following formula: Tumor volume $\left(\mathrm{mm}^{3}\right)=$ length $(\mathrm{mm}) \times$ width $(\mathrm{mm}) \times$ width $(\mathrm{mm}) \times 1 / 2$. Data are presented as mean \pm SD. When a tumor was not detectible, the tumor response was considered as complete remission. All treated mice were sacrificed on day 25 , and tumors were resected for further histological evaluation [15].

\section{Histological examination}

Fresh tumor samples were fixed in $10 \%$ formalin and embedded in paraffin before sectioning and staining. Tissue sections $(5 \mu \mathrm{m})$ were deparaffinized in xylene and rehydrated in an ethanol series. Hematoxylin and eosin ( $\mathrm{H} \& \mathrm{E})$ staining was performed according to standard protocols. Histological examination was performed with a BHS System Microscope (Olympus Corporation, Tokyo, Japan). Images were acquired with INFINITY ANALYZE software (Lumenera Corporation, Ottawa, Canada) [15].

\section{Statistical analysis}

SPSS statistics version 21.0 was used for all statistical analyses (IBM, New York City, NY, USA). Significant differences for continuous variables were determined using the Student's $t$-test. A probability value of $P<0.05$ was considered statistically significant [15]. 


\section{CONFLICTS OF INTEREST}

The authors declare no conflicts of interest.

\section{Dedication}

This paper is dedicated to the memory of A.R. Moossa, M.D. and Sun Lee, M.D.

\section{REFERENCES}

1. Zhao M, Yang M, Li X-M, Jiang P, Baranov E, Li S, Xu M, Penman S, Hoffman RM. Tumor-targeting bacterial therapy with amino acid auxotrophs of GFP-expressing Salmonella typhimurium. Proc Natl Acad Sci USA 2005;102:755-760.

2. Toneri M, Miwa S, Zhang Y, Hu C, Yano S, Matsumoto Y, Bouvet M, Nakanishi H, Hoffman RM, Zhao M. Tumortargeting Salmonella typhimurium A1-R inhibits human prostate cancer experimental bone metastasis in mouse models. Oncotarget. 2015;6:31335-31343. doi: 10.18632/ oncotarget.5866.

3. Zhao M, Geller J, Ma H, Yang M, Penman S, Hoffman RM. Monotherapy with a tumor-targeting mutant of Salmonella typhimurium cures orthotopic metastatic mouse models of human prostate cancer. Proc Natl Acad Sci USA 2007; 104:10170-10174.

4. Zhao M, Yang M, Ma H, Li X, Tan X, Li S, Yang Z, Hoffman RM. Targeted therapy with a Salmonella typhimurium leucine-arginine auxotroph cures orthotopic human breast tumors in nude mice. Cancer Res 2006;66:7647-7652.

5. Zhang Y, Tome Y, Suetsugu A, Zhang L, Zhang N, Hoffman RM, Zhao M. Determination of the optimal route of administration of Salmonella typhimurium A1-R to target breast cancer in nude mice. Anticancer Res 2012;32:2501-2508.

6. Zhang Y, Miwa S, Zhang N, Hoffman RM, Zhao M. Tumortargeting Salmonella typhimurium A1-R arrests growth of breast-cancer brain metastasis. Oncotarget. 2015;6:26152622. doi: 10.18632/oncotarget.2811.

7. Nagakura C, Hayashi K, Zhao M, Yamauchi K, Yamamoto N, Tsuchiya H, Tomita K, Bouvet M, Hoffman RM. Efficacy of a genetically-modified Salmonella typhimurium in an orthotopic human pancreatic cancer in nude mice. Anticancer Res 2009;29:1873-1878.

8. Yam C, Zhao M, Hayashi K, Ma H, Kishimoto H, McElroy M, Bouvet M, Hoffman RM. Monotherapy with a tumortargeting mutant of Salmonella typhimurium inhibits liver metastasis in a mouse model of pancreatic cancer. J Surg Res 2010;164:248-255.

9. Hiroshima Y, Zhao M, Zhang Y, Maawy A, Hassanein MK, Uehara F, Miwa S, Yano S, Momiyama M, Suetsugu A, Chishima T, Tanaka K, Bouvet M, et al. Comparison of efficacy of Salmonella typhimurium A1-R and chemotherapy on stem-like and non-stem human pancreatic cancer cells. Cell Cycle 2013;12:2774-2780.

10. Hiroshima Y, Zhao M, Maawy A, Zhang Y, Katz MH, Fleming JB, Uehara F, Miwa S, Yano S, Momiyama M, Suetsugu A, Chishima T, Tanaka K, et al. Efficacy of Salmonella typhimurium A1-R versus chemotherapy on a pancreatic cancer patient-derived orthotopic xenograft (PDOX). J Cell Biochem 2014;115:1254-1261.

11. Hiroshima Y, Zhang Y, Murakami T, Maawy AA, Miwa S, Yamamoto M, Yano S, Sato S, Momiyama M, Mori R, Matsuyama R, Chishima T, Tanaka K, et al. Efficacy of tumor-targeting Salmonella typhimurium A1-R in combination with anti-angiogenesis therapy on a pancreatic cancer patient-derived orthotopic xenograft (PDOX) and cell line mouse models. Oncotarget. 2014;5:12346-12357. doi: 10.18632/oncotarget.2641.

12. Matsumoto Y, Miwa S, Zhang Y, Hiroshima Y, Yano S, Uehara F, Yamamoto M, Toneri M, Bouvet M, Matsubara H, Hoffman RM, Zhao M. Efficacy of tumor-targeting Salmonella typhimurium A1-R on nude mouse models of metastatic and disseminated human ovarian cancer. J Cell Biochem 2014;115:1996-2003.

13. Matsumoto Y, Miwa S, Zhang Y, Zhao M, Yano S, Uehara F, Yamamoto M, Hiroshima Y, Toneri M, Bouvet M, Matsubara $\mathrm{H}$, Tsuchiya H, Hoffman RM. Intraperitoneal administration of tumor-targeting Salmonella typhimurium A1-R inhibits disseminated human ovarian cancer and extends survival in nude mice. Oncotarget. 2015;6:11369-11377. doi: 10.18632/ oncotarget.3607.

14. Hiroshima Y, Zhao M, Zhang Y, Zhang N, Maawy A, Murakami T, Mii S, Uehara F, Yamamoto M, Miwa S, Yano S, Momiyama M, Mori R, et al. Tumor-targeting Salmonella typhimurium A1-R arrests a chemo-resistant patient softtissue sarcoma in nude mice. PLoS One 2015;10:e0134324.

15. Murakami T, DeLong J, Eilber FC, Zhao M, Zhang Y, Zhang N, Singh A, Russell T, Deng S, Reynoso J, Quan C, Hiroshima Y, Matsuyama R, et al. Tumor-targeting Salmonella typhimurium A1-R in combination with doxorubicin eradicate soft tissue sarcoma in a patientderived orthotopic xenograft PDOX model. Oncotarget. 2016;7:12783-12790. doi: 10.18632/oncotarget.7226.

16. Kimura H, Zhang L, Zhao M, Hayashi K, Tsuchiya H, Tomita K, Bouvet M, Wessels J, Hoffman RM. Targeted therapy of spinal cord glioma with a genetically-modified Salmonella typhimurium. Cell Proliferation 2010;43:41-48.

17. Momiyama M, Zhao M, Kimura H, Tran B, Chishima T, Bouvet M, Hoffman RM. Inhibition and eradication of human glioma with tumor-targeting Salmonella typhimurium in an orthotopic nude-mouse model. Cell Cycle 2012;11:628-632.

18. Hayashi K, Zhao M, Yamauchi K, Yamamoto N, Tsuchiya H, Tomita K, Kishimoto H, Bouvet M, Hoffman RM. Systemic targeting of primary bone tumor and lung metastasis of high-grade osteosarcoma in nude mice with 
a tumor-selective strain of Salmonella typhymurium. Cell Cycle 2009;8:870-875.

19. Zhang Y, Miwa S, Zhang N, Hoffman RM, Zhao M. Tumortargeting Salmonella typhimurium A1-R arrests growth of breast-cancer brain metastasis. Oncotarget. 2015;6:26152622. doi: 10.18632/oncotarget.2811.

20. Miwa S, Yano S, Zhang Y, Matsumoto Y, Uehara F, Yamamoto M, Hiroshima Y, Kimura H, Hayashi K, Yamamoto N, Bouvet M, Tsuchiya H, Hoffman RM., et al. Tumor-targeting Salmonella typhimurium A1-R prevents experimental human breast cancer bone metastasis in nude mice. Oncotarget 2014;5:7119-7125. doi: 10.18632/ oncotarget.2226.

21. Hiroshima Y, Zhang Y, Zhao M, Zhang N, Murakami T, Maawy A, Mii S, Uehara F, Yamamoto M, Miwa S, Yano S, Momiyama M, Mori R, et al. Tumor-targeting Salmonella typhimurium A1-R in combination with Trastuzumab eradicates HER-2-positive cervical cancer cells in patientderived mouse models. PLoS One 2015;10:e0120358.

22. Yamamoto M, Zhao M, Hiroshima Y, Zhang Y, Shurell E, Eilber FC, Bouvet M, Noda M, Hoffman RM. Efficacy of tumor-targeting Salmonella typhimurium A1-R on a melanoma patient-derived orthotopic xenograft (PDOX) nude-mouse model. PLoS One 2016;11:e160882.

23. Kiyuna T, Murakami T, Tome Y, Kawaguchi K, Igarashi K, Zhang Y, Zhao M, Li Y, Bouvet M, Kanaya F, Singh A, Dry S, Eilber FC, et al. High efficacy of tumor-targeting Salmonella typhimurium A1-R on a doxorubicin- and dactolisib-resistant follicular dendritic-cell sarcoma in a patient-derived orthotopic xenograft PDOX nude mouse model. Oncotarget. 2016;7:33046-33054. doi: 10.18632/ oncotarget. 8848 .

24. Whelan J, McTiernan A, Cooper N, Wong YK, Francis M, Vernon S, Strauss SJ. Incidence and survival of malignant bone sarcomas in England 1979-2007. Int J Cancer 2012;131:E508-E517.

25. Luetke A, Meyers PA, Lewis I, Juergens H. Osteosarcoma treatment - where do we stand? A state of the art review. Cancer Treat Rev 2014;40:523-532.

26. Wilhelm SM, Carter C, Tang L, Wilkie D, McNabola A, Rong H, Chen C, Zhang X, Vincent P, McHugh M, Cao Y, Shujath J, Gawlak S, et al. BAY 43-9006 exhibits broad spectrum oral antitumor activity and targets the RAF/MEK/ERK pathway and receptor tyrosine kinases involved in tumor progression and angiogenesis. Cancer Res 2004;64:7099-7109.

27. Maki RG, D'Adamo DR, Keohan ML, Saulle M, Schuetze SM, Undevia SD, Livingston MB, Cooney MM, Hensley ML, Mita MM, Takimoto CH, Kraft AS, Elias AD, et al. Phase II study of sorafenib in patients with metastatic or recurrent sarcomas. J Clin Oncol 2009;27:3133-3140.

28. Roberts NJ, Zhang L, Janku F, Collins A, Bai RY, Staedtke V, Rusk AW, Tung D, Miller M, Roix J, Khanna KV, Murthy
R, Benjamin RS, et al. Intratumoral injection of Clostridium novyi-NT spores induces antitumor responses. Sci Transl Med 2014;6:249ra111.

29. Hoffman RM, editor. Bacterial Therapy of Cancer: Methods and Protocols. Methods in Molecular Biology 2016;1409. Walker, John M., series ed. Humana Press (Springer Science+Business Media New York).

30. Kimura H, Tome Y, Momiyama M, Hayashi K, Tsuchiya H, Bouvet M, Hoffman RM. Imaging the inhibition by anti- $\beta 1$ integrin antibody of lung seeding of single osteosarcoma cells in live mice. Int J Cancer 2012;131:2027-2033.

31. Uehara F, Tome Y, Miwa S, Hiroshima Y, Yano S, Yamamoto M, Mii S, Maehara H, Bouvet M, Kanaya F, Hoffman RM. Osteosarcoma cells enhance angiogenesis visualized by color-coded imaging in the in vivo Gelfoam ${ }^{\circledR}$ assay. J Cell Biochem 2014;115:1490-1494.

32. Tome Y, Tsuchiya H, Hayashi K, Yamauchi K, Sugimoto N, Kanaya F, Tomita K, Hoffman RM. In vivo gene transfer between interacting human osteosarcoma cell lines is associated with acquisition of enhanced metastatic potential. J Cell Biochem 2009;108:362-367.

33. Uehara F, Tome Y, Yano S, Miwa S, Mii S, Hiroshima Y, Bouvet M, Maehara H, Kanaya F, Hoffman RM. A colorcoded imaging model of the interaction of $\alpha_{\mathrm{v}}$ integrin-GFP expressed in osteosarcoma cells and RFP expressing blood vessels in Gelfoam ${ }^{\circledR}$ vascularized in vivo. Anticancer Res 2013;33:1361-1366.

34. Tome Y, Sugimoto N, Yano S, Momiyama M, Mii S, Maehara H, Bouvet M, Tsuchiya H, Kanaya F, Hoffman RM. Real-time imaging of $\alpha_{v}$ integrin molecular dynamics in osteosarcoma cells in vitro and in vivo. Anticancer Res 2013;33:3021-3025.

35. Tome Y, Kimura H, Maehara H, Sugimoto N, Bouvet M, Tsuchiya H, Kanaya F, Hoffman RM. High lungmetastatic variant of human osteosarcoma cells, selected by passage of lung metastasis in nude mice, is associated with increased expression of $\alpha_{v} \beta_{3}$ integrin. Anticancer Res 2013;33:3623-3627.

36. Uehara F, Tome Y, Miwa S, Hiroshima Y, Yano S, Yamamoto M, Mii S, Maehara H, Bouvet M, Kanaya F, Hoffman RM. Osteosarcoma cells enhance angiogenesis visualized by color-coded imaging in the in vivo Gelfoam ${ }^{\circledR}$ assay. J Cell Biochem 2014;115:1490-1494.

37. Miwa S, Hiroshima Y, Yano S, Zhang Y, Matsumoto Y, Uehara F, Yamamoto M, Kimura H, Hayashi K, Bouvet M, Tsuchiya H, Hoffman RM. Fluorescence-guided surgery improves outcome in an orthotopic osteosarcoma nudemouse model. J Orthopaedic Res 2014;32:1596-1601.

38. Tome Y, Yano S, Sugimoto N, Mii S, Uehara F, Miwa S, Bouvet M, Tsuchiya H, Kanaya F, Hoffman RM. Use of $\alpha_{v}$ integrin linked to green fluorescent protein in osteosarcoma cells and confocal microscopy to image molecular dynamics 
during lung metastasis in nude mice. Anticancer Res 2016;36:3811-3816.

39. Blagosklonny MV. Matching targets for selective cancer therapy. Drug Discov Today 2003;8:1104-1107.

40. Blagosklonny MV. Teratogens as anti-cancer drugs. Cell Cycle 2005;4:1518-1521.

41. Blagosklonny MV. Treatment with inhibitors of caspases, that are substrates of drug transporters, selectively permits chemotherapy-induced apoptosis in multidrug-resistant cells but protects normal cells. Leukemia 2001;15:936-941.

42. Blagosklonny MV. Target for cancer therapy: proliferating cells or stem cells. Leukemia 2006;20:385-391.
43. Apontes $\mathrm{P}$, Leontieva $\mathrm{OV}$, Demidenko $\mathrm{ZN}$, Li $\mathrm{F}$, Blagosklonny MV. Exploring long-term protection of normal human fibroblasts and epithelial cells from chemotherapy in cell culture. Oncotarget. 2011;2:222-233. doi: 10.18632/oncotarget.248.

44. Blagosklonny MV. Tissue-selective therapy of cancer. Br J Cancer 2003;89:1147-1151.

45. Yamauchi $\mathrm{K}$, Yang $\mathrm{M}$, Jiang $\mathrm{P}, \mathrm{Xu} \mathrm{M}$, Yamamoto N, Tsuchiya H, Tomita K, Moossa A,R, Bouvet M, Hoffman RM. Development of real-time subcellular dynamic multicolor imaging of cancer cell trafficking in live mice with a variable-magnification whole-mouse imaging system. Cancer Res 2006; 66:4208-4214. 